\title{
Características da paisagem da sub-bacia do rio Escondido, Amazônia sul-ocidental,
}

\section{Brasil}

\author{
Landscape characteristics in the Escondido river sub-basin, south-western Amazon, Brazil \\ Características del paisaje en la subcuenca del río Escondido, sur de la amazonia occidental, Brasil
}

Recebido: 24/02/2021 | Revisado: 03/03/2021 | Aceito: 04/03/2021 | Publicado: 14/03/2021

\author{
Jhony Vendruscolo \\ ORCID: https://orcid.org/0000-0003-3043-0581 \\ Universidade Federal do Amazonas, Brasil \\ E-mail: jhonyvendruscolo@gmail.com \\ Nara Rúbia Vieira Boone \\ ORCID: https://orcid.org/0000-0001-8585-4731 \\ Universidade Federal de Rondônia, Brasil \\ E-mail: nr_rubia@hotmail.com \\ Renan Fernandes Moreto \\ ORCID: https://orcid.org/0000-0001-8432-9388 \\ Engenheiro Florestal, Brasil \\ E-mail: renanfmoreto@gmail.com \\ Nilson Reinaldo Fernandes dos Santos Junior \\ ORCID: https://orcid.org/0000-0001-8607-3689 \\ Engenheiro Florestal, Brasil \\ E-mail: nilsonrfs.junior@gmail.com \\ Gilderlon dos Santos Soares \\ ORCID: https://orcid.org/0000-0001-8205-2709 \\ Klabin S/A, Brasil \\ E-mail: gil_mtd@hotmail.com \\ Ariane Cristine Rebelo Lima \\ ORCID: http://orcid.org/0000-0001-8839-0987 \\ Universidade Federal de Rondônia, Brasil \\ E-mail: ariane.crlima94@gmail.com \\ Wanderson Cleiton Schmidt Cavalheiro \\ ORCID: https://orcid.org/0000-0003-1356-8511 \\ Cavalheiro Engenharia Rural, Brasil \\ Empresarial LTDA, Brasil \\ E-mail: engflo.ro@gmail.com \\ Marta Silvana Volpato Sccoti \\ ORCID: https://orcid.org/0000-0001-5979-3218 \\ Universidade Federal de Rondônia, Brasil \\ E-mail: martasccoti@unir.br \\ Emanuel Maia \\ ORCID: https://orcid.org/0000-0002-5493-2183 \\ Universidade Federal de Rondônia, Brasil \\ E-mail: emanuel@unir.br \\ Francisco Adilson dos Santos Hara \\ ORCID: https://orcid.org/0000-0002-3215-953X \\ Universidade Federal do Amazonas, Brasil \\ E-mail: fhara@ufam.edu.br
}

\begin{abstract}
Resumo
A realização de atividades agropecuárias é essencial para o crescimento econômico da sociedade, contudo, deve integrar o uso racional dos recursos naturais para se tornar sustentável. Deste modo, é necessário conhecer as condições ambientais na paisagem para planejar adequadamente seu manejo. Diante do exposto, teve-se por objetivo realizar um levantamento detalhado das características da paisagem na sub-bacia do rio Escondido, Amazônia sul-ocidental. Para tanto, foram analisadas as características geométricas, topográficas e hidrográficas, com os softwares QGIS, Google Earth e TrackMaker Free, imagens altimétricas do satélite ALOS e dados da literatura. A sub-bacia do rio Escondido tem área de 1.595,66 $\mathrm{km}^{2}$, perímetro de $233,98 \mathrm{~km}$, forma alongada, baixa suscetibilidade de enchentes, altitudes de 182 a 597 m, predominância de relevos planos a ondulados $(93,69 \%)$, rede de drenagem de 4.183,09 km, padrão dendrítico de $8^{\mathrm{a}}$ ordem, média densidade de nascentes, alta densidade de drenagem, canal principal sinuoso, baixo coeficiente de manutenção e alto tempo de concentração. Essas características denotam elevado potencial para o desenvolvimento de atividades agropecuárias, todavia, é recomendada uma análise da dinâmica da cobertura do solo, considerando
\end{abstract}


as características topográficas e hidrográficas da sub-bacia do rio Escondido, para delimitar as áreas prioritárias para conservação e recuperação da vegetação nativa. Também se recomenda o uso das microbacias como subunidades de gestão da sub-bacia do rio Escondido, por apresentarem características de paisagem diferenciadas que influenciam as práticas de manejo e, consequentemente, a eficiência da gestão dos recursos naturais.

Palavras-chave: Geotecnologias; Recursos naturais; Planejamento e gestão ambiental.

\begin{abstract}
The performance of agricultural activities is essential for the economic growth of society. However, it must integrate the rational use of natural resources to become sustainable. Thus, it is necessary to know the environmental conditions in the landscape to plan its management. Given the above, the objective was to carry out a detailed survey of the characteristics of the landscape in the sub-basin of the Escondido River, south-western Amazon. For that, the geometric, topographic, and hydrographic characteristics were analyzed, with the software QGIS, Google Earth, and TrackMaker Free, altimetric images from the ALOS satellite, and data from the literature. The Escondido River sub-basin has an area of $1,595.66 \mathrm{~km}^{2}$, a perimeter of $233.98 \mathrm{~km}$, an elongated shape, low susceptibility to flooding, altitudes of 182 to $597 \mathrm{~m}$, predominance of flat to undulating reliefs $(93.69 \%)$, drainage network of $4,183.09 \mathrm{~km}, 8$ th order dendritic pattern, medium spring density, high drainage density, winding main channel, low maintenance coefficient and high concentration time. These characteristics show a high potential for the development of agricultural activities, however, an analysis of the soil cover dynamics is recommended, considering the topographic and hydrographic characteristics of the Escondido river sub-basin, to delimit the priority areas for conservation and recovery of native vegetation. The use of micro-basins as management subunits of the Escondido sub-basin is also recommended, as they have different landscape characteristics that influence management practices and, consequently, the efficiency of natural resource management.
\end{abstract}

Keywords: Geotechnologies; Natural resources; Environmental planning and management.

\title{
Resumen
}

El desarrollo de las actividades agrícolas es fundamental para el crecimiento económico de la sociedad, y debe integrar el uso racional de los recursos naturales, para que sea sostenible. Por ello, es necesario conocer los recursos naturales disponibles en el paisaje para planificar adecuadamente su manejo. Dado lo anterior, el trabajo tiene como objetivo realizar un relevamiento detallado de las características del paisaje en la subcuenca del río Escondido, sur de la Amazonia Occidental. Para el levantamiento se analizaron las características geométricas, topográficas e hidrográficas con el software QGIS, Google Earth y TrackMaker Free, imágenes altimétricas del satélite ALOS y datos de la literatura. La subcuenca del río Escondido tiene un área de 1.595,66 $\mathrm{km}^{2}$, un perímetro de 233,98 km, forma alargada, baja susceptibilidad a inundaciones, altitudes de 182 a $597 \mathrm{~m}$, predominio de relieves planos a ondulados $(93,69 \%)$, red de drenaje de 4.183,09 km, patrón dendrítico de octavo orden, media densidad de manantiales, densidad de drenaje alta, canal principal sinuoso, bajo coeficiente de mantenimiento y alto tiempo de concentración. Estas características muestran un alto potencial para el desarrollo de actividades agrícolas, sin embargo, se recomienda un análisis de la dinámica de la cobertura del suelo, considerando las características topográficas e hidrográficas de la subcuenca del río Escondido, para delimitar las áreas prioritarias para la conservación y recuperación de la vegetación nativa. También se recomienda utilizar microcuencas como sub-unidades de manejo de la subcuenca del río Escondido, ya que tienen diferentes características paisajísticas que influyen en las prácticas de manejo y, en consecuencia, en la eficiencia del manejo de los recursos naturales.

Palabras clave: Geotecnologías; Recursos naturales; Planificación y gestión ambiental.

\section{Introdução}

O manejo dos recursos naturais é considerado o primeiro passo para o desenvolvimento sustentável das atividades humanas, e pode ser realizado de forma eficiente quando se utiliza a bacia hidrográfica como unidade de gestão. A bacia hidrográfica é uma área de captação natural da precipitação pluviométrica, delimitada pelas cotas mais elevadas do relevo, composta por um conjunto de nascentes e uma rede de drenagem que direcionam o fluxo hídrico para um único ponto, conhecido como exutório (Tucci, 2004). As bacias podem ser fragmentadas em sub-bacias, para facilitar o detalhamento das características da paisagem e, consequentemente, o manejo dos recursos naturais.

O estado de Rondônia tem sete bacias hidrográficas que deságuam no rio Amazonas, conhecidas como Abunã, Guaporé, Jamari, Machado, Madeira, Mamoré e Roosevelt. A bacia do Guaporé é composta por dez sub-bacias (Fernandes \& Guimarães, 2002), das quais se destaca a sub-bacia do rio Escondido, por estar inserida no Território do Cone Sul, conhecido pelo grande 
potencial de desenvolvimento do agronegócio (Silva \& Dandolini, 2018). A sub-bacia do rio Escondido abrange aproximadamente 1.453 propriedades rurais (INCRA, 2019), que necessitam de informações da paisagem para auxiliar no desenvolvimento das atividades agropecuárias.

O detalhamento das características da paisagem pode ser realizado por meio de sensoriamento remoto, obtendo-se informações de qualidade em tempo hábil e com baixo custo financeiro (Kabite \& Gessesse, 2018, Soares, et al., 2019), quando comparado com levantamentos de campo. As informações disponibilizadas pelo Sistema de Informação Geográfica (SIG), permitem a elaboração de mapas digitais precisos, que podem ser cruzados entre si ou com outras informações (Cavallari, Tamae \& Rosa, 2007). Assim, é possível delimitar áreas prioritárias para a preservação e conservação dos recursos naturais, áreas com aptidão agrícola e selecionar as melhores práticas de manejo do solo e da água (Silva, et al., 2021), como pode ser observado nos trabalhos de Vendruscolo et al. (2019), Santos et al. (2019) e Moreto et al. (2019).

Em face ao exposto, o presente trabalho tem como objetivo realizar um levantamento detalhado das características da paisagem na sub-bacia do rio Escondido, Amazônia sul-ocidental, a fim de fornecer informações para a gestão dos recursos naturais da região.

\section{Metodologia}

\subsection{Localização e características da área}

A área de estudo é a sub-bacia do rio Escondido, localizada nos municípios de Colorado D’Oeste (48,79\%), Cabixi (45,15\%), Pimenteiras D'Oeste (5,81\%), Cerejeiras (0,11\%), Vilhena 0,09\%), Corumbiara $(0,04 \%)$ e Chupinguaia $(<0,01 \%)$, estado de Rondônia (Figura 1). A região tem clima do tipo Monção (Am) (Alvares, et al., 2014), precipitação anual de 1.728,9 a 1.843,7 mm (Franca, 2015), temperatura média anual de $23,7{ }^{\circ} \mathrm{C}$, umidade relativa média anual de $80 \%$ (SEDAM, 2012), e vegetação nativa de transição, biomas de Cerrado e Floresta Amazônica (Miranda, et al., 2006). 
Figura 1. Localização da sub-bacia do rio Escondido, Rondônia, Brasil.

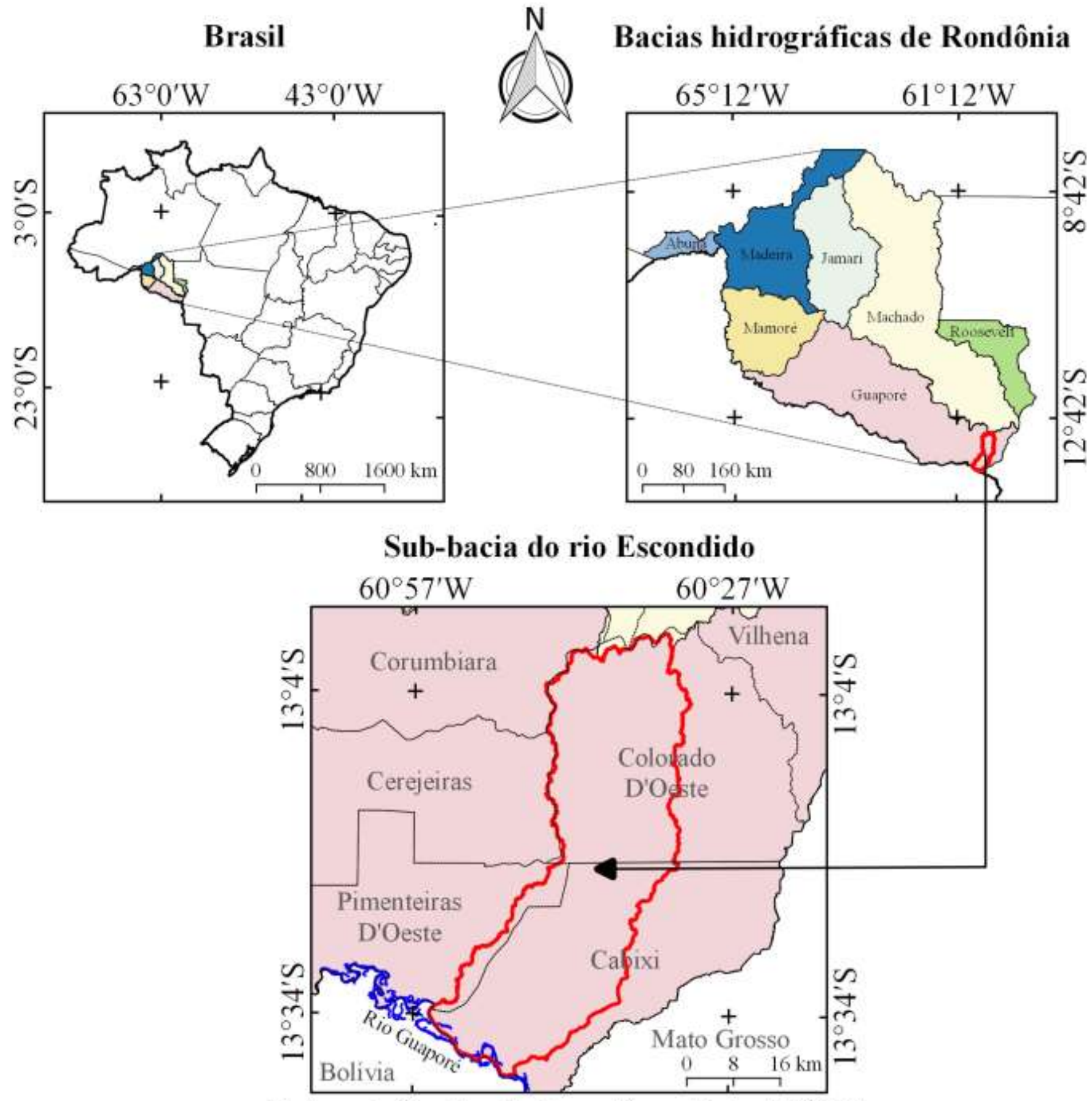

Sistema de Coordenadas Geográficas - Datum WGS 84

Fonte: Autores.

\subsection{Características da paisagem}

No trabalho foram utilizados métodos quantitativos e qualitativos, visto que, o primeiro permite atribuir valores numéricos para as características da paisagem, enquanto o segundo permite a interpretação e a elaboração de opiniões sobre estes valores (Pereira et al., 2018). As características da paisagem analisadas estão associadas aos parâmetros geométricos (área, perímetro, fator de forma, coeficiente de compacidade e índice de circularidade), topográficos (altitude e relevo) e hidrográficos (padrão de drenagem, ordem dos cursos d'água, densidade de nascentes, densidade de drenagem, índice de sinuosidade, coeficiente de manutenção e tempo de concentração). A aquisição destas informações ocorreu em sete etapas, descritas a seguir: 
1ªpa: edição da rede de drenagem com a ferramenta "Adicionar caminho" do software Google Earth. As trilhas foram salvas em formato Keyhole Markup Language (KML), unidas com a ferramenta "Lápis” no software TrackMaker Free (TMF) e ordenadas com a ferramenta “Strahler” no software QGIS 2.10.1 (versão Pisa) (QGIS Development Team, 2015). Em seguida, identificou-se o padrão da rede de drenagem por meio de uma comparação entre a distribuição espacial da rede de drenagem em estudo e os principais padrões de redes de drenagem fornecidos por Parvis (1950).

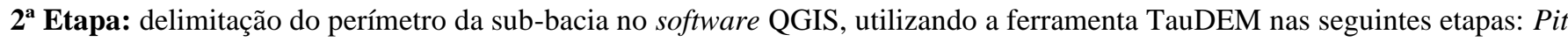
Remove < D8 Flow Directions < D8 Contributing Area $\left(1^{\circ}\right.$ versão $)<$ Stream Definition By Threshold < Criação do ponto de exutório < D8 Contributing Area ( $2^{\circ}$ versão). O arquivo do perímetro da sub-bacia foi gerado em formato matricial, em seguida foi convertido para o formato vetorial com a ferramenta "Poligonizar", dissolvido com a ferramenta "Dissolver", e no software Google Earth, ajustado de acordo com as características da paisagem. Posteriormente, foram calculados a área e o perímetro com a ferramenta "Calculadora de campo".

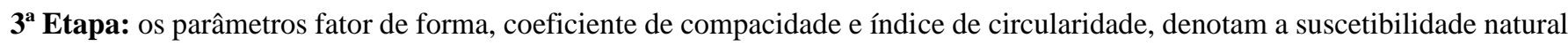
a enchentes da sub-bacia, e foram calculados com as Equações 1, 2 (Villela \& Mattos, 1975) e 3 (Christofoletti, 1980).

$$
F=\frac{A}{L^{2}}
$$

(Equação 1)

Onde: $\mathrm{F}$ = fator de forma; $\mathrm{A}=$ área de drenagem da sub-bacia $\left(\mathrm{km}^{2}\right)$; e $\mathrm{L}=$ comprimento do eixo da sub-bacia $(\mathrm{km})$.

$$
K c=0,28 x \frac{P}{\sqrt{A}}
$$

Onde: $\mathrm{Kc}=$ coeficiente de compacidade; $\mathrm{P}=$ perímetro da sub-bacia $(\mathrm{km}) ; \mathrm{e} \mathrm{A}=$ área de drenagem da sub-bacia $\left(\mathrm{km}^{2}\right)$.

$$
I c=\frac{12,57 \times A}{P^{2}}
$$

Onde: $\mathrm{IC}=$ índice de circularidade; $\mathrm{A}=$ área de drenagem da sub-bacia $\left(\mathrm{km}^{2}\right)$; e $\mathrm{P}=$ perímetro da sub-bacia $(\mathrm{km})$.

Para a análise destes parâmetros levou-se em consideração a rede de drenagem do principal rio da sub-bacia para a aquisição da área e perímetro, tendo em vista que existem mais de um exutório na região em estudo.

4 ${ }^{a}$ Etapa: mensurações das altitudes mínima e máxima, diretamente da imagem altimétrica do satélite ALOS (Sensor Palsar) (ASF, 2017), e da altitude média com a ferramenta "Estatística por Zona", no software QGIS. Em seguida, mensuração da declividade na paisagem utilizando as imagens altimétricas e a ferramenta "Modelo Digital de Elevação".

5a Etapa: mensurações da densidade de nascentes e da densidade de drenagem, com as Equações 4 (Christofoletti, 1980) e 5 (Horton, 1932), respectivamente.

$$
D n=\frac{N}{A}
$$


Onde: $\mathrm{Dn}=$ densidade de nascentes $\left(\right.$ nascentes $\left.\mathrm{km}^{-2}\right) ; \mathrm{N}=$ número de nascentes; $\mathrm{A}=$ área da sub-bacia $\left(\mathrm{km}^{2}\right)$.

$$
D d=\frac{L}{A}
$$

Onde: $\mathrm{Dd}=$ densidade de drenagem $\left(\mathrm{km} \mathrm{km}^{-2}\right) ; \mathrm{L}=$ comprimento da rede de drenagem $(\mathrm{km}) ; \mathrm{A}=$ área da sub-bacia $\left(\mathrm{km}^{2}\right)$.

$6^{\mathbf{a}}$ Etapa: mensurações do índice de sinuosidade, coeficiente de manutenção e tempo de concentração, com as Equações 6 (Villela \& Mattos, 1975), 7 (Santos, et al., 2012) e 8 (Kirpich, 1940, apud Targa, et al., 2012).

$$
I s=\frac{L-D v}{L} x 100
$$

Onde: Is = índice de sinuosidade (\%); $\mathrm{L}=$ comprimento do canal principal $(\mathrm{km}) ; \mathrm{Dv}=$ distância vetorial do canal principal $(\mathrm{km})$.

$$
C m=\frac{1}{D d} x 1000
$$

(Equação 7)

Onde: $\mathrm{Cm}=$ coeficiente de manutenção $\left(\mathrm{m}^{2} \mathrm{~m}^{-1}\right) ; \mathrm{Dd}=$ densidade de drenagem $\left(\mathrm{km} \mathrm{km}^{-2}\right)$

$$
T c=57 x\left(\frac{L^{3}}{H}\right)^{0,385}
$$

Onde: $\mathrm{Tc}=$ tempo de concentração (minutos); $\mathrm{L}=$ comprimento do talvegue principal $(\mathrm{km}) ; \mathrm{H}=$ desnível entre a parte mais elevada e a seção de controle (m).

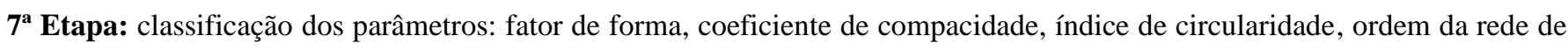
drenagem, densidade de nascentes, densidade de drenagem, índice de sinuosidade e relevo, com dados da literatura (Tabela 1). 
Tabela 1. Valores de referência para classificação de parâmetros geométricos, topográficos e hidrográficos.

\begin{tabular}{|c|c|c|c|c|}
\hline Parâmetro & Unidade & Limite & Classe & Autores \\
\hline Fator de forma $(\mathrm{F})$ & - & $\begin{array}{c}<0,50 \\
0,50-0,75 \\
0,76-1,00\end{array}$ & $\begin{array}{c}\text { Não sujeito a enchentes } \\
\text { Tendência média a enchentes } \\
\text { Sujeito a enchentes }\end{array}$ & 1 \\
\hline Coeficiente de compacidade (Kc) & - & $\begin{array}{l}1,00-1,25 \\
1,26-1,50 \\
\quad>1,50\end{array}$ & $\begin{array}{l}\text { Alta propensão a enchentes } \\
\text { Tendência média a enchentes } \\
\text { Não sujeito a enchentes }\end{array}$ & 1 \\
\hline Índice de circularidade (Ic) & - & $\begin{array}{c}<0,51 \\
0,51-0,75 \\
0,76-1,00\end{array}$ & $\begin{array}{l}\text { Forma alongada } \\
\text { Forma intermediária } \\
\text { Forma circular }\end{array}$ & 2 \\
\hline Ordem da rede de drenagem & - & $\begin{array}{c}1 \\
2 \\
3 \\
\geq 4\end{array}$ & $\begin{array}{l}\text { Improvável habitat de peixes } \\
\text { Baixas condições para habitação } \\
\text { Moderadas condições para habitação } \\
\text { Elevadas condições para habitação }\end{array}$ & 3 \\
\hline $\begin{array}{l}\text { Densidade de nascentes } \\
\text { (Dn) }\end{array}$ & $\begin{array}{l}\text { nascentes } \\
\mathrm{km}^{-2}\end{array}$ & $\begin{array}{c}<3 \\
3-7 \\
7-15 \\
>15\end{array}$ & $\begin{array}{c}\text { Baixa } \\
\text { Média } \\
\text { Alta } \\
\text { Muito alta }\end{array}$ & 4 \\
\hline $\begin{array}{l}\text { Densidade de drenagem } \\
\text { (Dd) }\end{array}$ & $\mathrm{km} \mathrm{km}^{-2}$ & $\begin{array}{c}<0,50 \\
0,50-2,00 \\
2,01-3,50 \\
>3,50\end{array}$ & $\begin{array}{l}\text { Baixa } \\
\text { Média } \\
\text { Alta } \\
\text { Muito alta }\end{array}$ & 5 \\
\hline $\begin{array}{l}\text { Índice de sinuosidade } \\
\text { (Is) }\end{array}$ & $\%$ & $\begin{array}{c}<20 \\
20-29 \\
30-39,9 \\
40-49,95 \\
>50\end{array}$ & $\begin{array}{l}\text { Muito reto } \\
\text { Reto } \\
\text { Divagante } \\
\text { Sinuoso } \\
\text { Muito sinuoso }\end{array}$ & 6 \\
\hline Relevo & $\%$ & $\begin{array}{c}0-3 \\
3-8 \\
8-20 \\
20-45 \\
45-75\end{array}$ & $\begin{array}{l}\text { Plano } \\
\text { Suave ondulado } \\
\text { Ondulado } \\
\text { Forte ondulado } \\
\text { Montanhoso } \\
\end{array}$ & 7 \\
\hline
\end{tabular}

Fontes: 1 - Lima Júnior, et al. (2012); 2 - Silva (2012); 3 - Adaptado de Fairfull \& Witheridge (2003); 4 - Lollo (1995); 5 - Beltrame (1994); 6 - Romero, Formiga \& Marcuzzo (2017); 7 - Santos et al. (2013).

\section{Resultados e Discussão}

A sub-bacia do rio Escondido é formada por 137 microbacias, destacando as microbacias dos rios Sete Voltas, Caiman, Santa Teresinha, Enganado, Alto Rio Escondido, Médio Rio Escondido e São Jorge, por abrangerem 21,05, 14,24, 11,19, 9,62, 9,18, 3,64 e 3,22\% da área da microbacia, respectivamente, perfazendo um acumulado de 72,14\% (Figura 2 e Tabela 2). 
Figura 2. Microbacias que compõem a sub-bacia do rio Escondido, Amazônia sul-ocidental, Brasil.

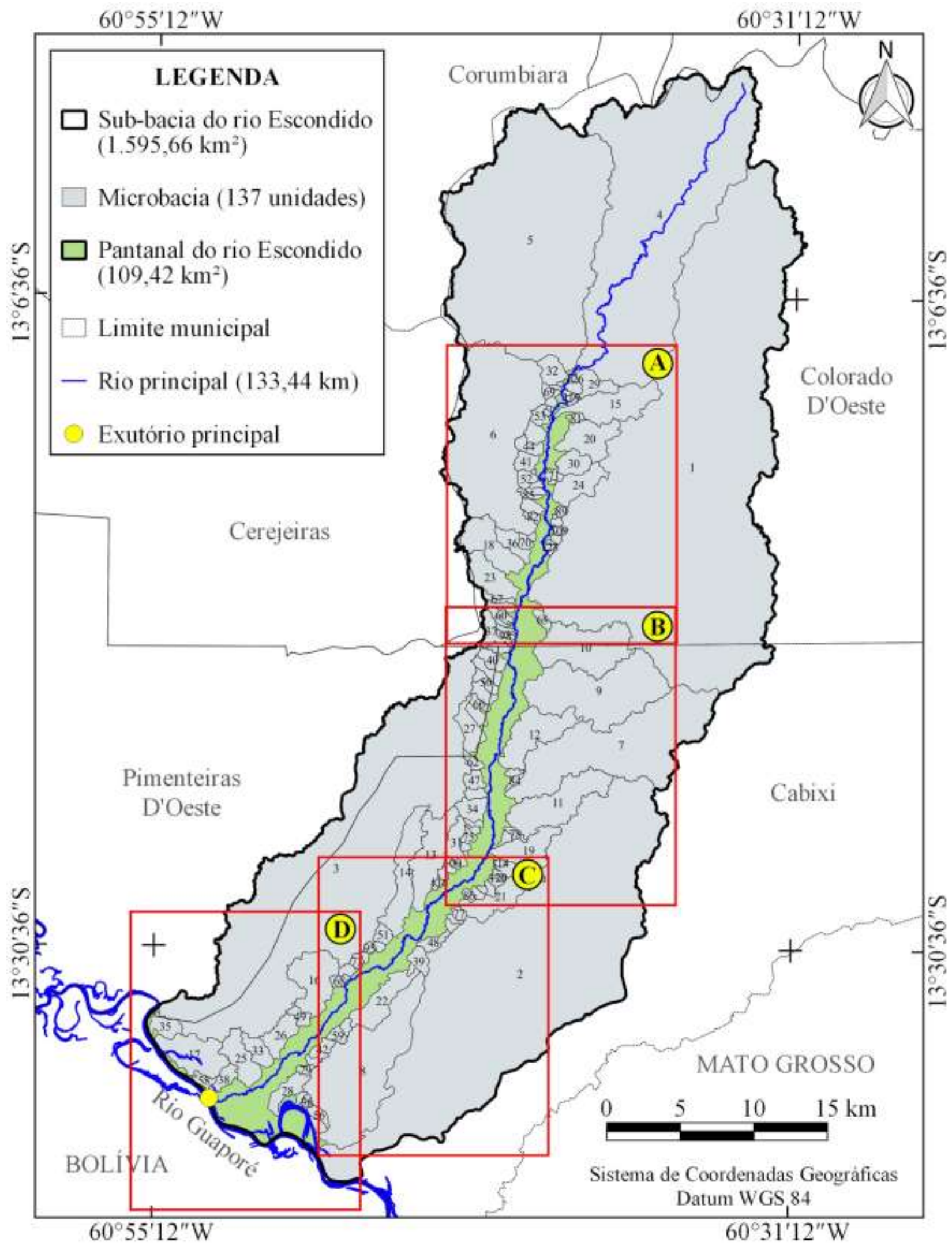


Research, Society and Development, v. 10, n. 3, e22210313253, 2021

(CC BY 4.0) | ISSN 2525-3409 | DOI: http://dx.doi.org/10.33448/rsd-v10i3.13253

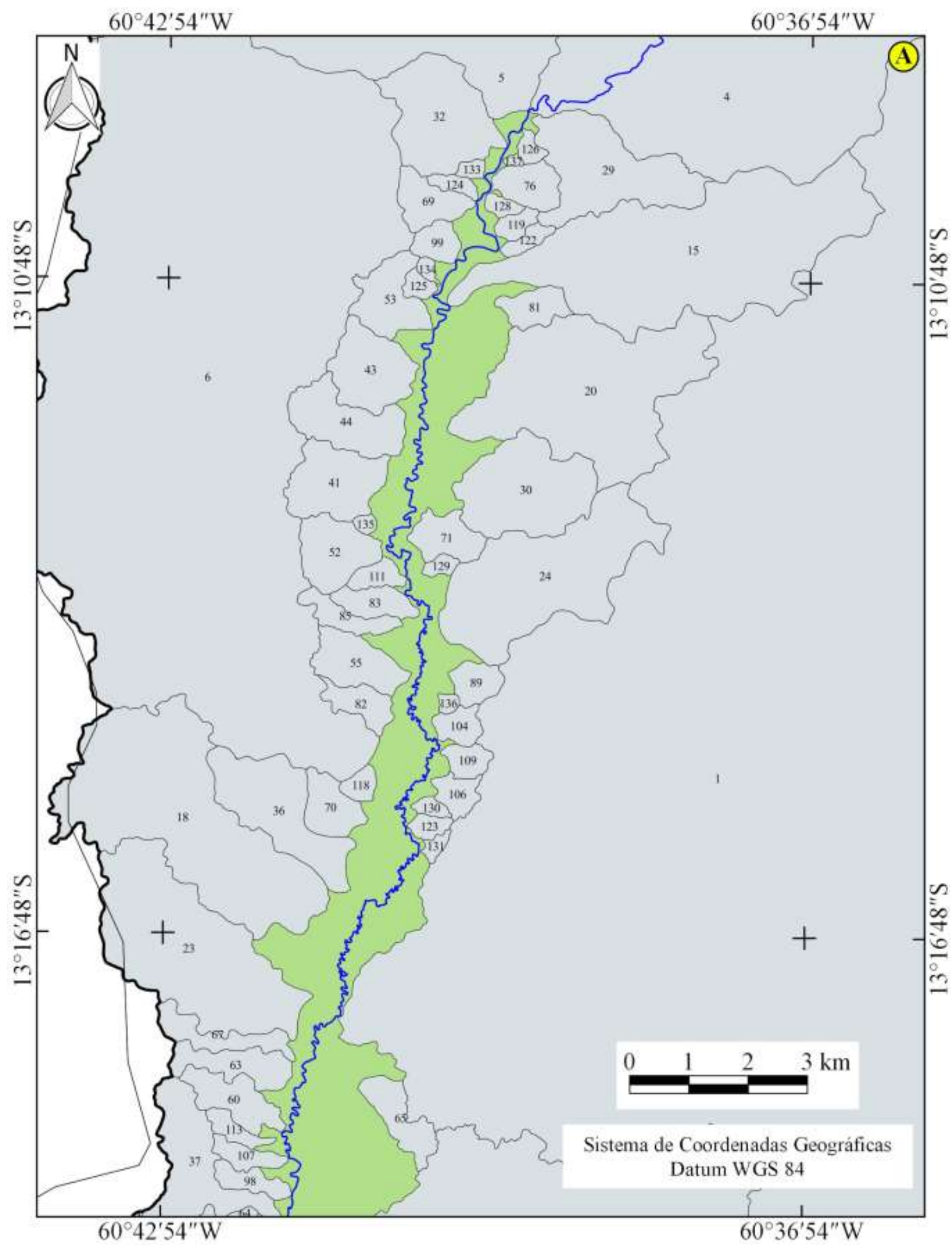


Research, Society and Development, v. 10, n. 3, e22210313253, 2021

(CC BY 4.0) | ISSN 2525-3409 | DOI: http://dx.doi.org/10.33448/rsd-v10i3.13253

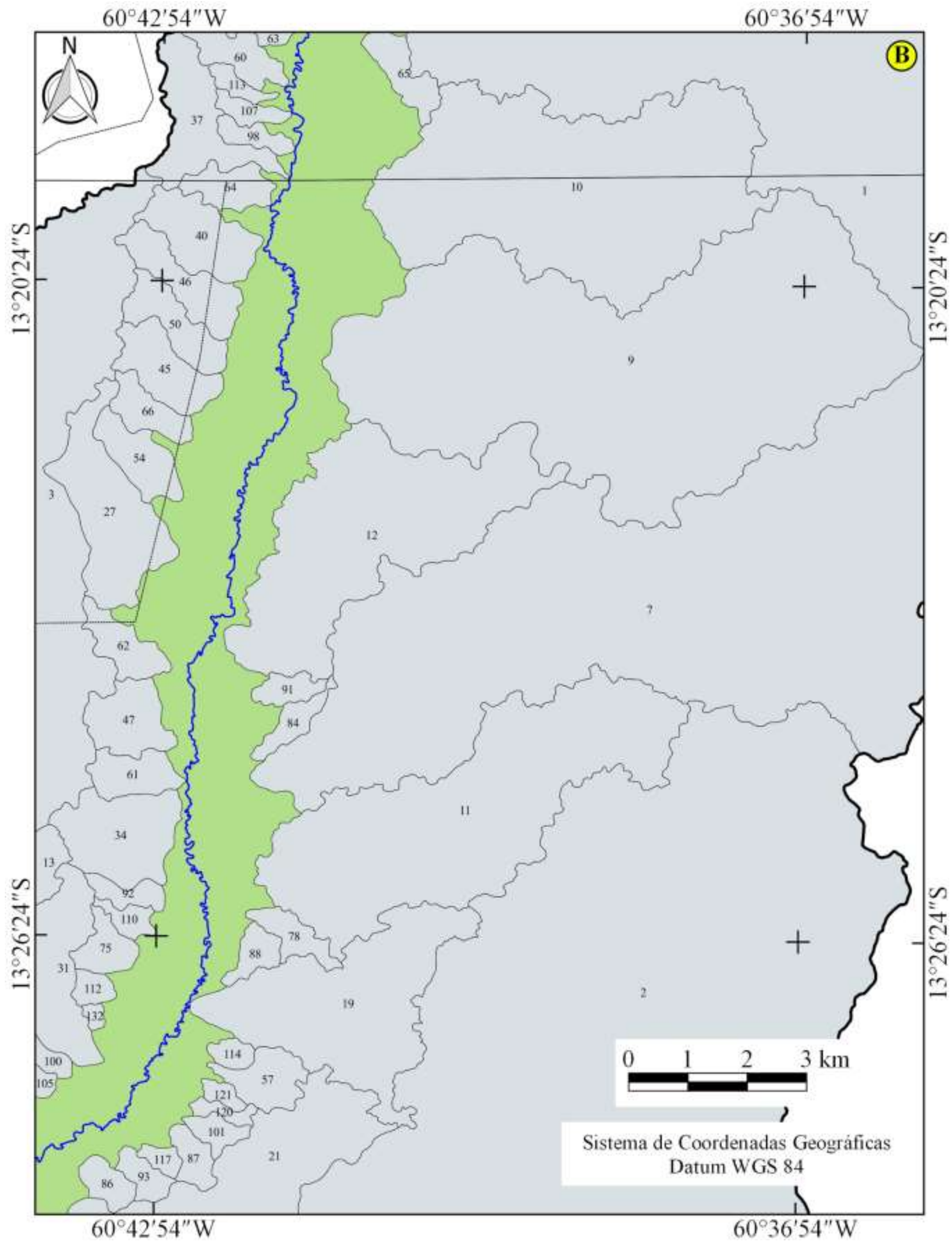


Research, Society and Development, v. 10, n. 3, e22210313253, 2021

(CC BY 4.0) | ISSN 2525-3409 | DOI: http://dx.doi.org/10.33448/rsd-v10i3.13253






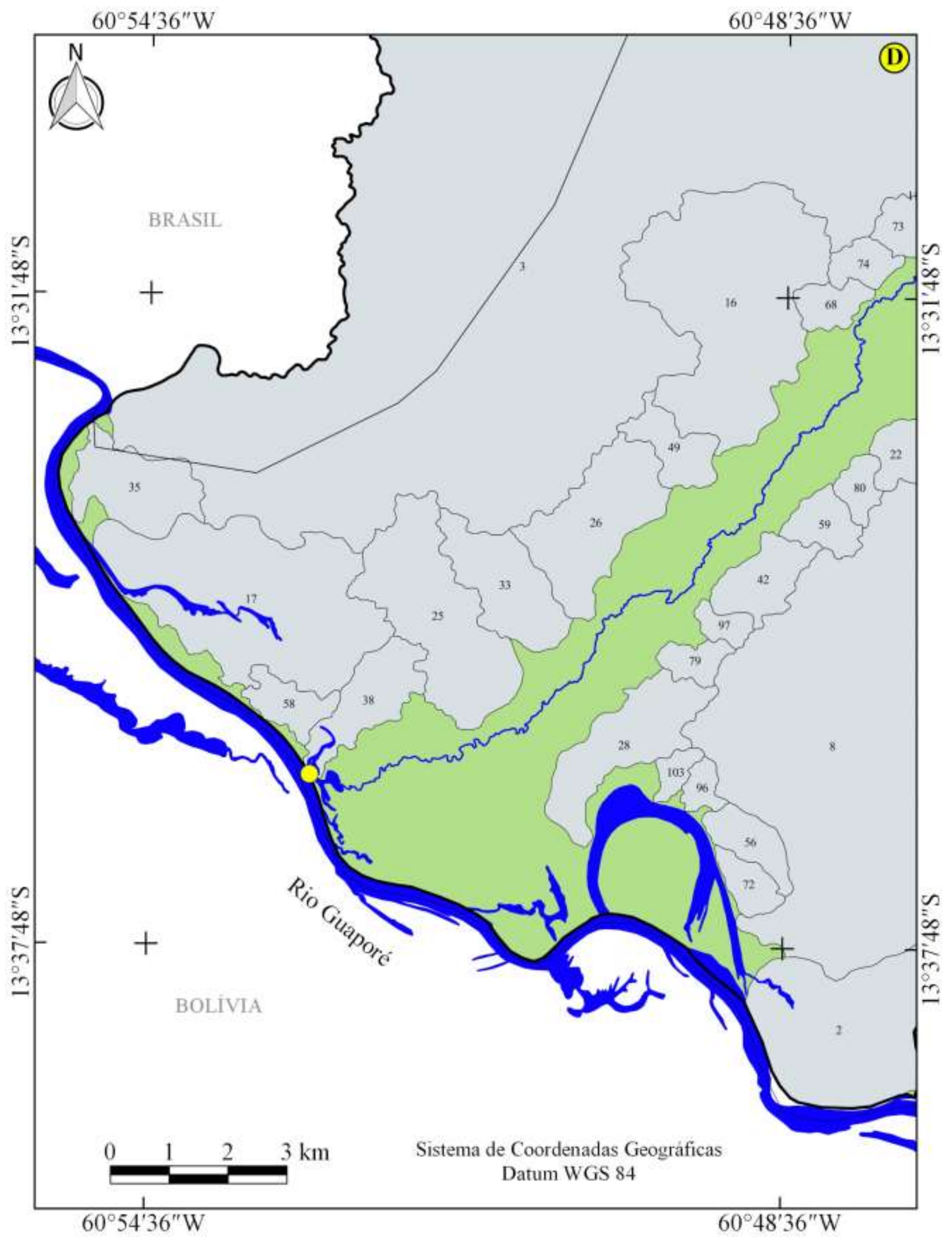

Fonte: Autores. 
Tabela 2. Microbacias que compõem a sub-bacia do rio Escondido, Amazônia sul-ocidental, Brasil.

\begin{tabular}{|c|c|c|c|c|c|c|c|c|c|c|c|}
\hline $\mathbf{N}$ & Microbacia & $\begin{array}{c}\text { Área } \\
\left(\mathbf{k m}^{2}\right)\end{array}$ & $\mathbf{N}$ & Microbacia & $\begin{array}{c}\text { Área } \\
\left(\mathbf{k m}^{2}\right)\end{array}$ & $\mathbf{N}$ & Microbacia & $\begin{array}{c}\text { Área } \\
\left(\mathbf{k m}^{2}\right)\end{array}$ & $\mathbf{N}$ & Microbacia & $\begin{array}{l}\text { Área } \\
\left(\mathbf{k m}^{2}\right)\end{array}$ \\
\hline & & & & & & & & & & & \\
\hline 1 & Sete Voltas & 335,96 & 36 & Rio Tatu & 2,649 & 71 & Corruíra & 0,800 & 106 & Rio da Cigana & 0,420 \\
\hline 2 & Caiman & 227,34 & 37 & Rio das Pombas & 2,442 & 72 & Surpresa & 0,790 & 107 & Rio Mandi & 0,414 \\
\hline 3 & Santa Teresinha & 178,49 & 38 & Rio Guapé & 2,136 & 73 & Rio Amendoim & 0,782 & 108 & Rio Cascudinho & 0,392 \\
\hline 4 & Enganado & 153,54 & 39 & Rio Muriçoca & 2,084 & 74 & Rio Mariposa & 0,773 & 109 & Rio Porco-espinho & 0,386 \\
\hline 5 & Alto Rio Escondido & 146,52 & 40 & Rio Camarão & 1,955 & 75 & Rio Papagaio & 0,748 & 110 & Rio Vazio & 0,384 \\
\hline 6 & Médio Rio Escondido & 58,031 & 41 & Tocandira & 1,742 & 76 & Rio Pequeno & 0,737 & 111 & Bicho-preguiça & 0,355 \\
\hline 7 & São Jorge & 51,317 & 42 & Rio Gralha & 1,637 & 77 & Rio da Miragem & 0,736 & 112 & Rio Percevejo & 0,346 \\
\hline 8 & Ariranha & 41,792 & 43 & Rio do Canário & 1,621 & 78 & Rio da Paineira & 0,717 & 113 & Rio Cascudo & 0,329 \\
\hline 9 & Rio das Almas & 31,739 & 44 & Rio do Bugio & 1,603 & 79 & Rio Novo & 0,681 & 114 & Rio da Malícia & 0,324 \\
\hline 10 & Tamanduá & 17,479 & 45 & Rio Pantanal & 1,572 & 80 & Rio Mosquito & 0,648 & 115 & Rio Borboleta & 0,319 \\
\hline 11 & Jacarandá & 15,071 & 46 & Rio Jaguatirica & 1,540 & 81 & Rio da Grota & 0,620 & 116 & Rio do Sapo & 0,291 \\
\hline 12 & Rio Coruja & 11,369 & 47 & Rio Ingá & 1,478 & 82 & Água Bela & 0,614 & 117 & Rio Urucum & 0,267 \\
\hline 13 & Rio Lagarto & 11,268 & 48 & Rio Carapanã & 1,426 & 83 & Rio Caramujo & 0,601 & 118 & Rio Guaxinim & 0,266 \\
\hline 14 & Rio Bodo & 11,243 & 49 & Rio Traíra & 1,331 & 84 & Estrela do Oeste & 0,584 & 119 & Rio do Calango & 0,263 \\
\hline 15 & Rio do Gato & 11,056 & 50 & Rio Doce & 1,319 & 85 & Rio Jiboia & 0,576 & 120 & Rio da Embaúba & 0,261 \\
\hline 16 & Água Bonita & 10,397 & 51 & Rio Vereda & 1,293 & 86 & Rio da Raposa & 0,567 & 121 & Rio Capeba & 0,255 \\
\hline 17 & Baia Preta & 9,821 & 52 & Rio Carijó & 1,292 & 87 & Rio Angelim & 0,556 & 122 & Rio do Mateiro & 0,248 \\
\hline 18 & Rio Paca & 8,878 & 53 & Rio Urubu & 1,235 & 88 & Rio da Enguia & 0,547 & 123 & Rio das Pererecas & 0,235 \\
\hline 19 & Rio do Caranguejo & 7,845 & 54 & Rio Buriti & 1,218 & 89 & Rio do Nambu & 0,518 & 124 & Rio Solitário & 0,218 \\
\hline 20 & Rio Bela Vista & 7,779 & 55 & Rio Formiga & 1,168 & 90 & Rio Guacho & 0,516 & 125 & Rio do Corvo & 0,204 \\
\hline 21 & Rio Pardal & 7,678 & 56 & Água Lenta & 1,111 & 91 & Rio do Descanso & 0,499 & 126 & Rio dos Sonhos & 0,188 \\
\hline 22 & Rio Duvidoso & 7,268 & 57 & Rio Sabugo & 1,087 & 92 & Rio Alegria & 0,499 & 127 & Rio Intermitente & 0,186 \\
\hline 23 & Joaninha & 6,500 & 58 & Rio Alagado & 1,061 & 93 & Rio Coleirinha & 0,498 & 128 & Rio Borrachudo & 0,177 \\
\hline 24 & Rio Curiango & 5,682 & 59 & Rio Jatobá & 1,042 & 94 & Rio Girino & 0,490 & 129 & Rio Saracura & 0,163 \\
\hline 25 & Rio Calmo & 5,589 & 60 & Rio Tucano & 1,024 & 95 & Rio Vaga-lume & 0,474 & 130 & Rio Lacre-vermelho & 0,156 \\
\hline 26 & Rio Jararaca & 4,034 & 61 & Rio Bacuri & 1,014 & 96 & Água Calma & 0,470 & 131 & Rio Garça-real & 0,141 \\
\hline 27 & Rio Urutau & 3,738 & 62 & Rio Açaí & 1,003 & 97 & Rio Curioso & 0,469 & 132 & Rio Micuim & 0,133 \\
\hline 28 & Cateto & 3,310 & 63 & Rio Carrapato & 0,996 & 98 & Rio Bagre & 0,462 & 133 & Rio Tapera & 0,130 \\
\hline 29 & Rio Passarinho & 3,271 & 64 & Rio Cupim & 0,915 & 99 & Rio Cajá & 0,457 & 134 & Rio Saudades & 0,106 \\
\hline 30 & Rio Taperebá & 3,130 & 65 & Rio dos Macacos & 0,915 & 100 & Rio Bambu & 0,456 & 135 & Rio Caninana & 0,104 \\
\hline 31 & Rio Taquara & 3,103 & 66 & Rio Esperança & 0,873 & 101 & Rio da Bandarra & 0,452 & 136 & Rio da Gota & 0,103 \\
\hline 32 & Pica-pau & 2,859 & 67 & Rio Gafanhoto & 0,847 & 102 & Rio Libélula & 0,439 & 137 & Rio Beija-flor & 0,049 \\
\hline 33 & Rio Biguá & 2,836 & 68 & Rio Bovino & 0,841 & 103 & Água Mansa & 0,439 & & & \\
\hline 34 & Rio Quero-quero & 2,666 & 69 & Rio do Peixe & 0,827 & 104 & Rio dos Preás & 0,428 & & & \\
\hline 35 & Rio Patuá & 2,651 & 70 & Rio Caracol & 0,824 & 105 & Rio Seco & 0,424 & & & \\
\hline
\end{tabular}

Fonte: Autores.

\subsection{Características geométricas}

A sub-bacia do rio Escondido tem área de $1.595,66 \mathrm{~km}^{2}$, perímetro de 267,25 km, fator de forma de 0,18, coeficiente de compacidade de 2,22 e índice de circularidade de 0,20. Os valores de área e perímetro assemelham-se aos encontrados por Fernandes \& Guimarães (2002), 1.717,46 km² e 225,79 km, respectivamente. A diferença entre os valores está relacionada com o método de delimitação da sub-bacia, os referidos autores provavelmente utilizaram a delimitação automática com imagens do projeto SRTM (90 m de resolução espacial), enquanto o presente estudo utilizou a delimitação automática com imagens do satélite Alos (12,5 m de resolução espacial) e imagens de alta resolução espacial, para o ajuste do perímetro. Os demais resultados denotam que a sub-bacia tem formato alongado e não é propensa a enchentes.

\subsection{Características topográficas}

Os valores de altitude variam de 182 a 597 m, com valor médio de 304 m (Figura 3). A altitude influencia na temperatura, evaporação e precipitação do ambiente (Villela \& Mattos, 1975). A temperatura pode ter reduções de 0,48 a $0,90^{\circ} \mathrm{C}$ a cada 100 m de ascensão vertical (Fritzons, Mantovani \& Aguiar, 2008; Fritzons, Where \& Mantovani, 2015; Fritzons, Mantovani \& Where, 2016). E a precipitação, pode ter um incremento com a elevação vertical (Duckstein, Fogel \& Thames, 1973), com média de $1 \mathrm{~mm}$ de chuva para cada 1,30 m de incremento na altitude (Nery Junior \& Vanzela, 2016). Neste contexto, é plausível supor 
que a sub-bacia em estudo pode ter temperaturas variando entre 22,8 e 24,6 ${ }^{\circ}$, e diferenças de até $319,23 \mathrm{~mm}$ entre as áreas de maior e menor altitude, contudo, recomenda-se estudos específicos para confirmar essa hipótese.

A altitude também exerce influência na adaptabilidade ambiental de espécies de interesse econômico (Figueiredo et al., 2015). Em trabalho realizado por Bourke (2010), foram identificadas muitas espécies que encontram-se na mesma faixa de altitude da sub-bacia do rio Escondido, como: Abelmoschus esculentus (quiabo), Ananas comosus (abacaxi), Arachis hypogaea (amendoim), Bixa orellana (urucum), Carica papaya (mamão), Glycine max (soja), Hevea brasiliensis (seringueira), Ipomoea batatas (batata-doce), Lycopersicon esculentum (tomate), Manihot esculenta (mandioca), Musa sp. (banana), Oryza sativa (arroz), Piper nigrum (pimenta-do-reino), Phaseolus vulgaris (feijão), Psidium guajava (goiaba), Ricinus communis (mamona), Saccharum officinarum (cana-de-açúcar), Theobroma cacao (cacau) e Zea mays (milho).

O relevo da sub-bacia varia de plano a escarpado, com predominância das classes suave ondulado (45,84\%), ondulado $(28,28 \%)$ e plano $(19,57 \%)$ (Figura 4). O relevo é a forma da superfície terrestre, e serve de embasamento para expansão da ação do homem sobre o espaço a partir da ocupação de novas áreas de assentamento para residências, estabelecimentos produtivos, vias de acesso e áreas de plantio e/ou criação (Girão \& Corrêa, 2004). Este elemento da paisagem também interfere em processos naturais como a erosão hídrica e a propagação de incêndios, além de influenciar o ponto gravitacional de veículos automotores e, consequentemente, a aptidão à mecanização agrícola em propriedades rurais. 
Figura 3. Mapa hipsométrico da sub-bacia do rio Escondido, Amazônia sul-ocidental, Brasil.

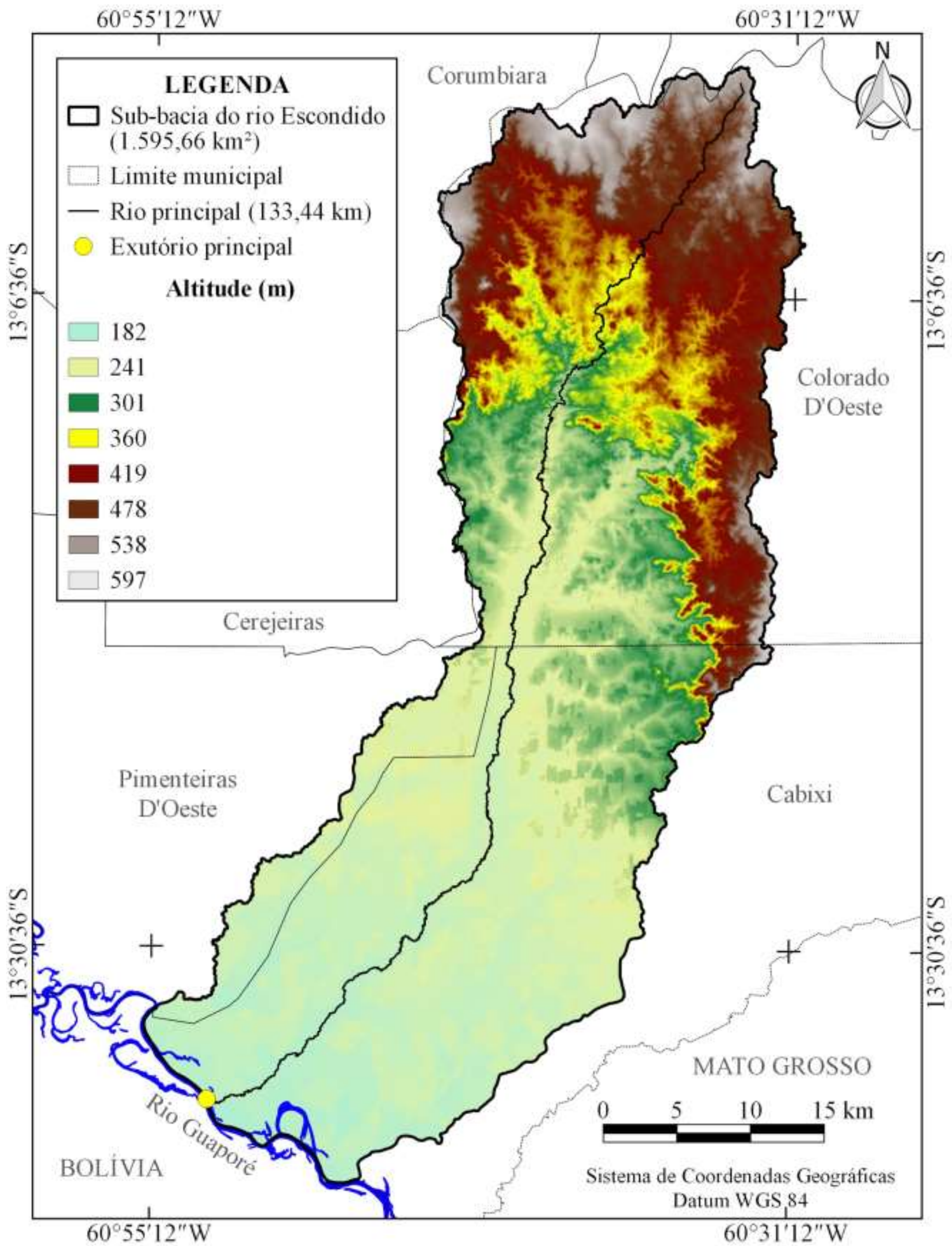

Fonte: Autores. 
Figura 4. Relevo na sub-bacia do rio Escondido, Amazônia sul-ocidental, Brasil.

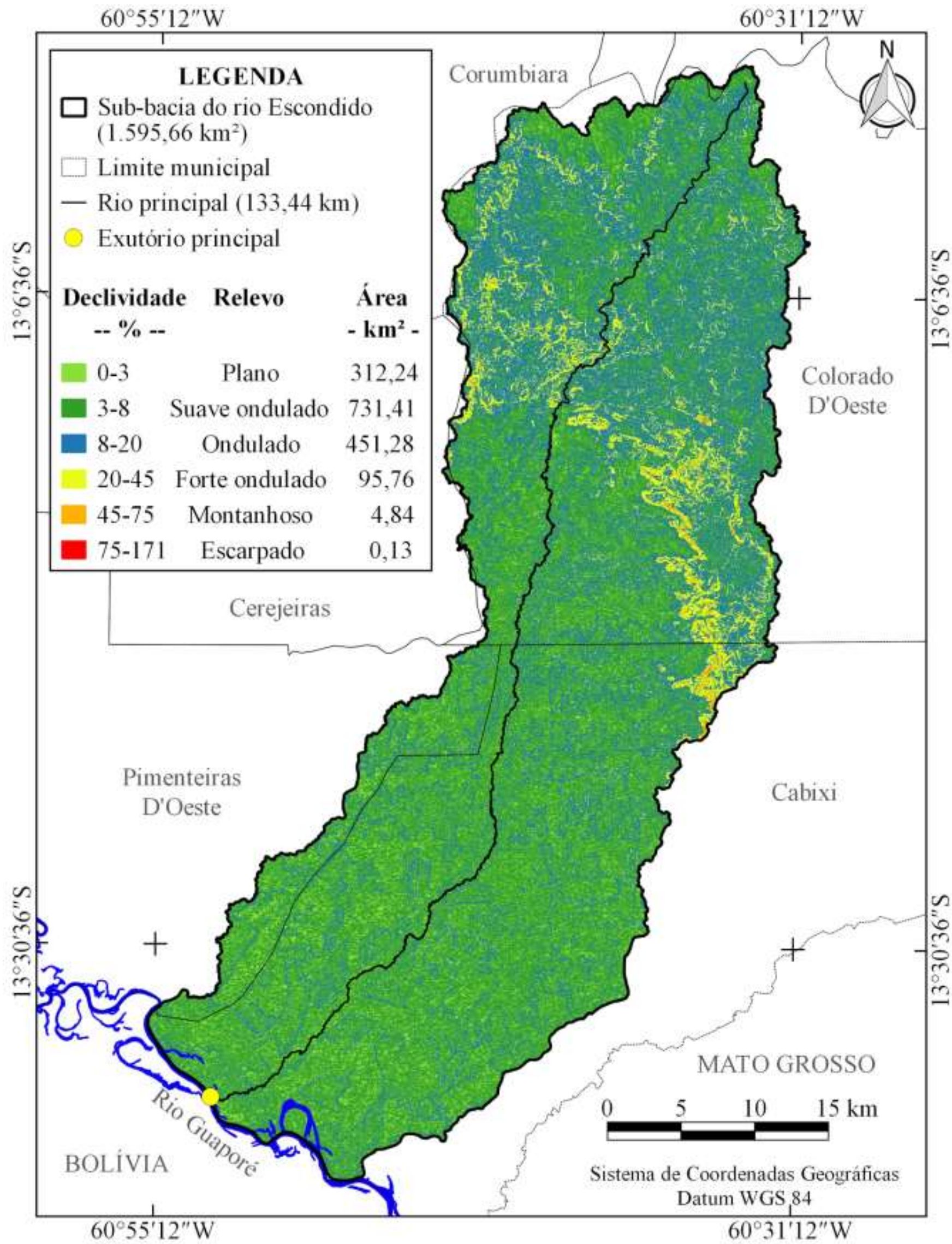

Fonte: Autores. 
O potencial de erosão hídrica tende a se elevar com a inclinação do terreno (Amorim, et al., 2001). Tem-se como exemplo, que a perda de solo em um ciclo do cultivo de soja em sistema convencional passou de $0,616 \mathrm{t} \mathrm{ha}^{-1}$, na declividade de 0 a $4 \%$, para $9,77 \mathrm{t} \mathrm{ha}^{-1}$ na declividade de 4 a $8 \%$, e para 11,497 $\mathrm{t} \mathrm{ha}^{-1}$ na declividade de 8 a $12 \%$ (Cogo, Levien \& Schwarz, 2003). Ao considerar essas informações, verifica-se que a sub-bacia em estudo poderia perder até 717.427,64 t de solo por ciclo, se fosse cultivada com soja em sistema convencional nas declividades de 0 a 12\%. Assim, observa-se a necessidade de adotar práticas de manejo conservacionista para reduzir possíveis problemas com erosões hídricas, principalmente nas áreas mais inclinadas. Como exemplo de práticas conservacionistas tem-se a correção e adubação do solo (edáfica), manutenção da cobertura vegetal (vegetativa), construção de terraços em curvas de nível e adoção de plantio em contorno (mecânicas) (Bertoni \& Lombardi Neto, 2014).

A propagação de incêndios aumenta com a inclinação do terreno, sendo observado que declividades $<15,16$ a 25, 26 a 35, 36 a 45 e > 46\%, correspondem abaixo, moderado, alto, muito alto e extremo risco, respectivamente (Ribeiro, et al., 2008). Essas informações indicam que a sub-bacia do rio Escondido tem 87,03, 9,64, 2,32, 0,70 e 0,31\% da área com baixo, moderado, alto, muito alto e extremo risco de propagação de incêndios, respectivamente. As áreas mais propensas à propagação estão localizadas na cabeceira da sub-bacia.

A aptidão das terras a mecanização agrícola pode ser classificada de acordo com a declividade em extremamente apta (0-5\%), muito apta (5,1-10\%), apta (10,1-15\%), moderadamente apta (15,1-20\%) e não recomendada (> 20\%) (Silva, et al., 2009). Neste contexto, a sub-bacia tem aproximadamente $42,14,32,01,12,89,6,65$ e 6,31\%, de áreas extremamente aptas, muito aptas, aptas, moderadamente aptas e não aptas à mecanização agrícola, respectivamente. Na região norte da sub-bacia, onde existe menor aptidão à mecanização agrícola, há predominância de pastagens, onde é exercida a atividade da pecuária de corte (Figura 5A). As áreas com maior aptidão à mecanização agrícola estão localizadas na região sul, próxima ao exutório, exatamente onde há a maior concentração de propriedades rurais com atividades de agronegócio (Figura 5B). 
Research, Society and Development, v. 10, n. 3, e22210313253, 2021

(CC BY 4.0) | ISSN 2525-3409 | DOI: http://dx.doi.org/10.33448/rsd-v10i3.13253

Figura 5. Atividades pecuárias na região norte (A) e agricultura mecanizada na região Sul (B) da sub-bacia do rio Escondido, Amazônia sul-ocidental, Brasil.
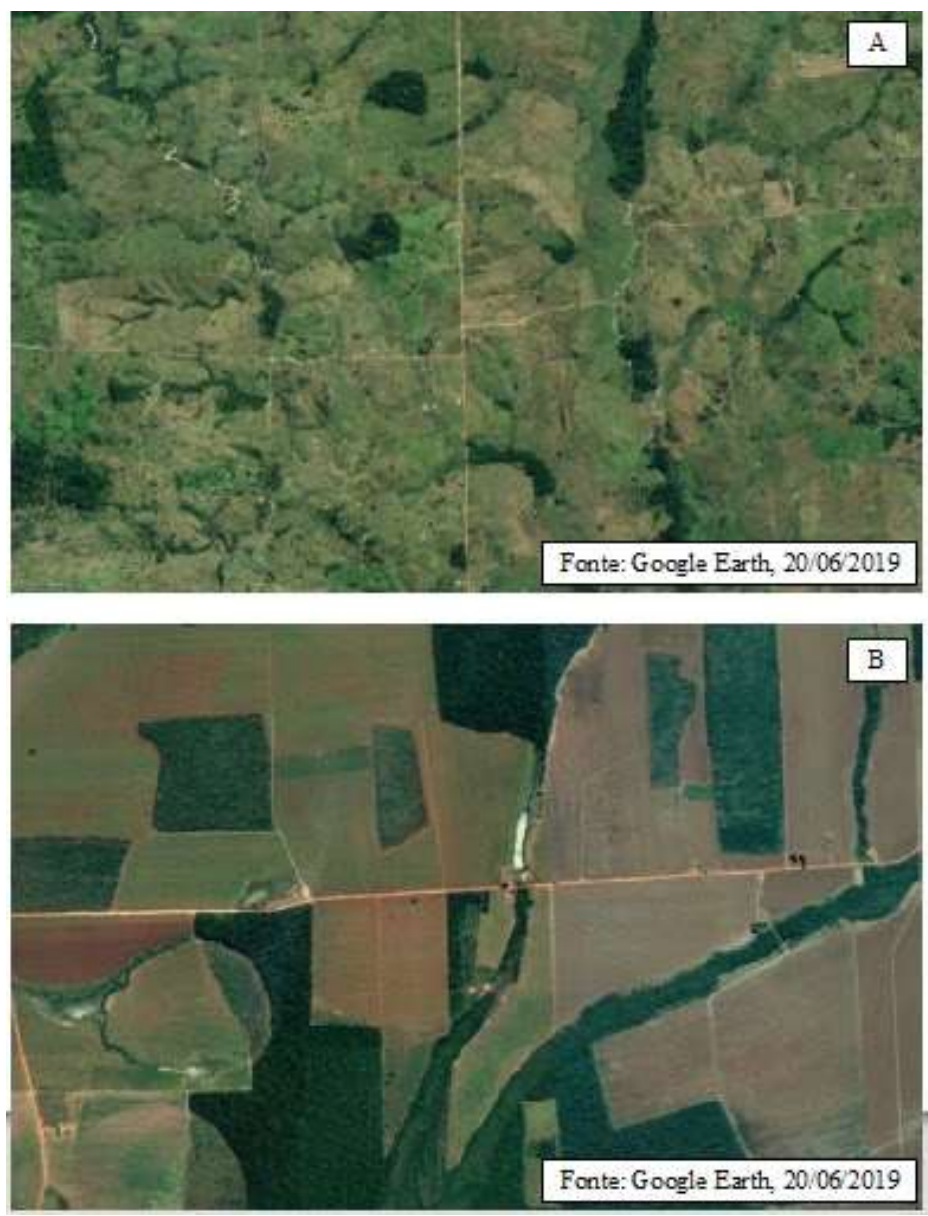

Fonte: Autores.

\subsection{Características hidrográficas}

A sub-bacia do rio Escondido tem rede de drenagem de 4.183,09 km (Figura 6), padrão dendrítico de $8^{\mathrm{a}}$ ordem, 6,06 nascentes $\mathrm{km}^{-2}$ (Figura 7), densidade de drenagem de 2,62 $\mathrm{km} \mathrm{km}^{-2}$, índice de sinuosidade de 41,63\%, coeficiente de manutenção de $381,5 \mathrm{~m}^{2} \mathrm{~m}^{-1}$ e tempo de concentração de $28,38 \mathrm{~h}$. 
Figura 6. Rede e ordem da drenagem na sub-bacia do rio Escondido, Amazônia sul-ocidental, Brasil.

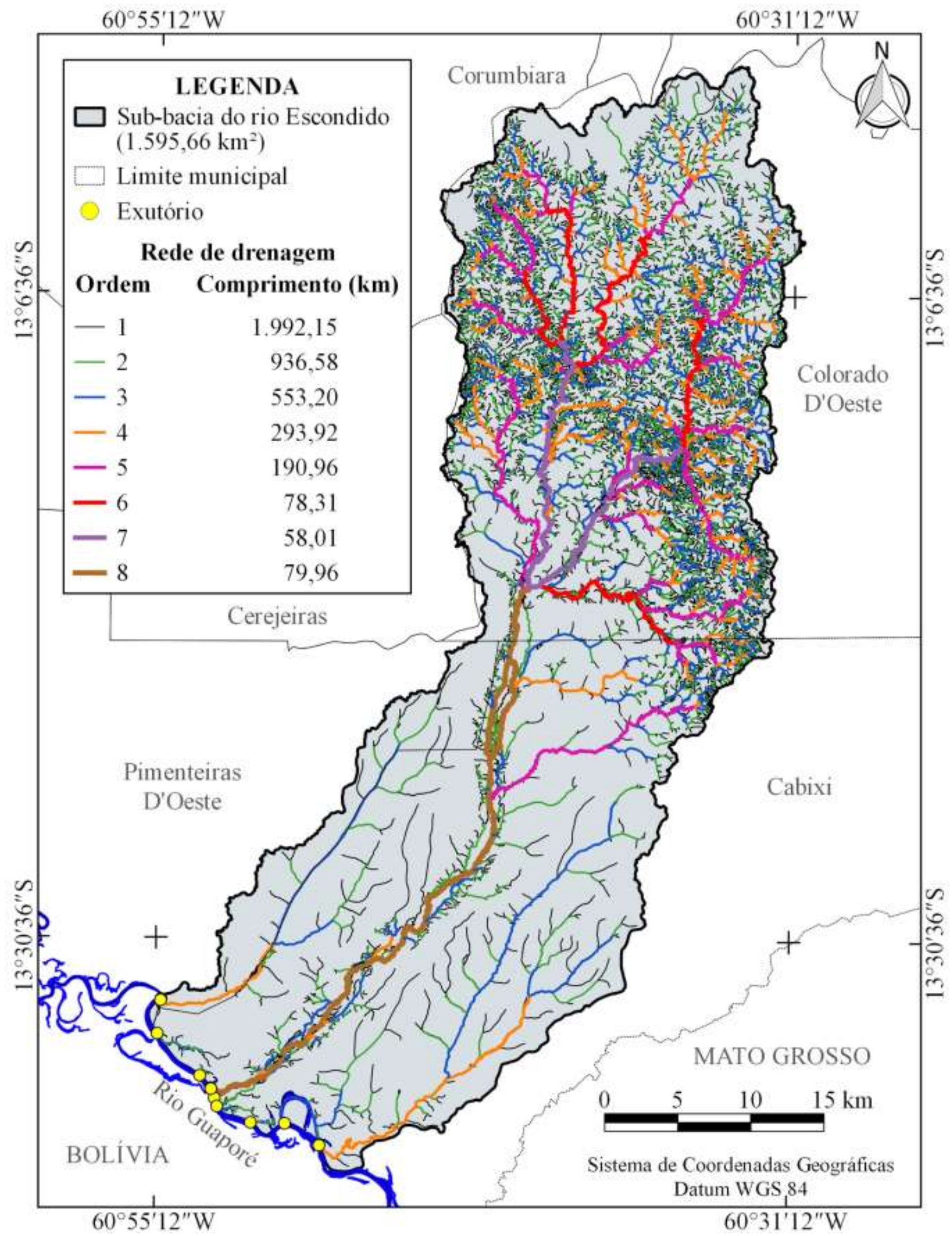

Fonte: Autores. 
Figura 7. Distribuição espacial das nascentes na sub-bacia do rio Escondido, Amazônia sul-ocidental, Brasil.

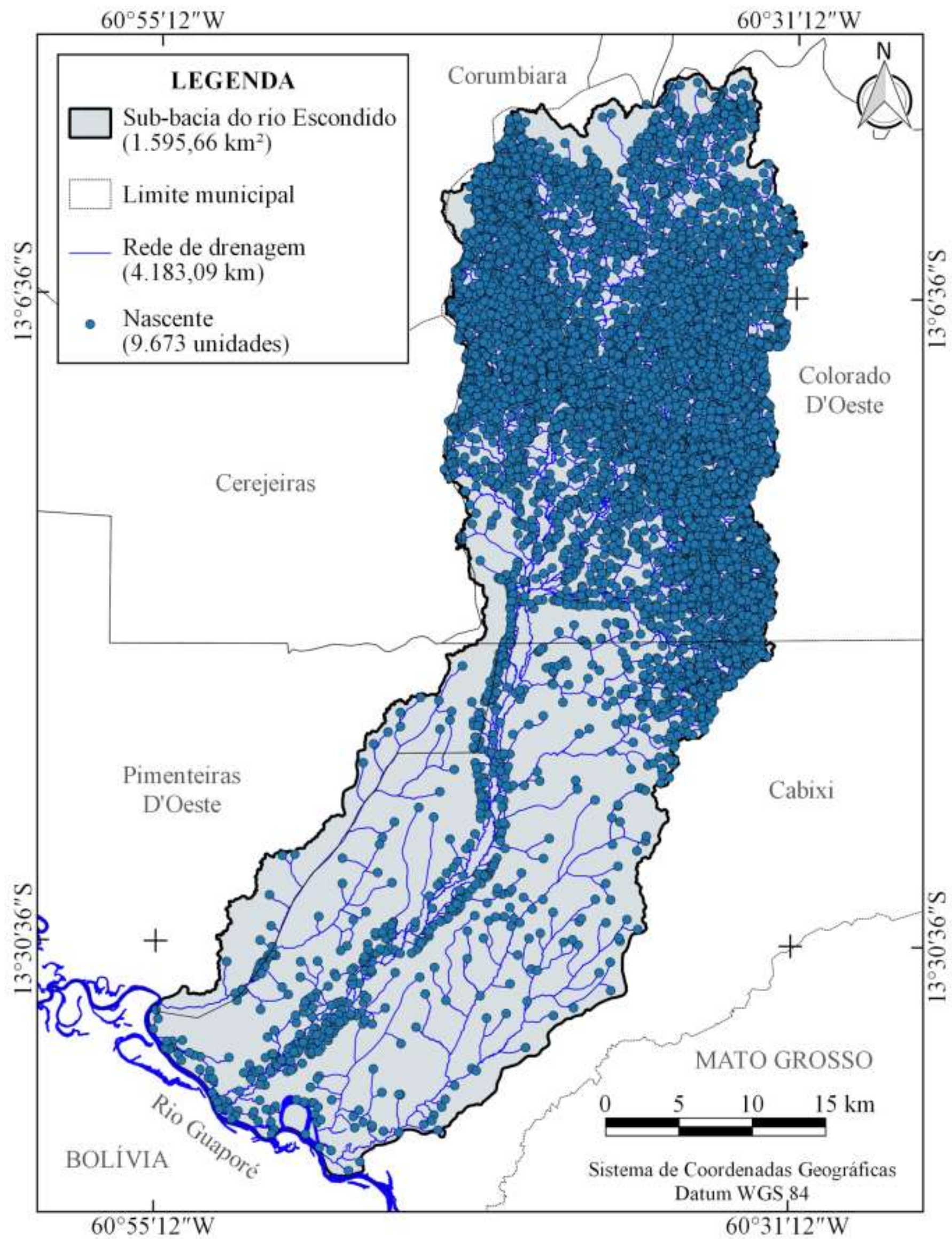

Fonte: Autores 
O padrão dendrítico indica que a formação dos drenos ocorreu sobre uma rocha horizontal homogênea (Parvis, 1950). De acordo com Smith (1943 apud Parvis, 1950), esse padrão assemelha-se a uma árvore, onde o rio principal corresponde ao tronco e seus tributários aos galhos, ramos e folhas.

Os rios de $8^{\mathrm{a}}$ ordem sugerem que há elevadas condições para habitação de peixes. A sub-bacia do rio Escondido é um afluente do rio Guaporé, e pode atuar como berçário de algumas espécies que necessitam de ambientes lóticos para a reprodução, assim como a sub-bacia do rio Branco. Como exemplo de espécies que ocorrem no rio Guaporé e necessitam de ambientes lóticos para a reprodução tem-se: piau (Leporinus sp.), curimbatá (Prochilodus nigricans), jatuarana (Brycon spp.), caparari (Pseudoplatystoma tigrinum Valenciennes) e surubim (Pseudoplatystoma fasciatum) (Doria, et al., 2008).

A densidade de nascentes indica a capacidade da bacia gerar novos cursos d'águas (Christofoletti, 1969). Neste contexto, verifica-se que a região tem média capacidade para gerar novos cursos d'água. Este parâmetro está relacionado com a declividade do terreno, sendo observado que o valor aumenta constantemente do relevo plano até o relevo montanhoso, como pode ser observado nas microbacias Alto Rio Escondido (Vendruscolo, et al., 2020a) e Médio Rio Escondido (Vendruscolo, et al., 2020b). A declividade potencializa à erosão hídrica (Cogo, Levien \& Schwarz, 2003), acarretando a formação de erosões laminares, que evoluem para sulco, ravina e voçoroca, chegando a atingir o nível do lençol freático com o passar do tempo (Guerra, 1997). Assim se origina uma nova nascente, e, consequentemente, um novo curso d'água.

A densidade de drenagem é considerada alta, denotando boa distribuição espacial dos recursos hídricos na região. Resultados semelhantes foram observados nas microbacias dos rios Manicoré (Vendruscolo, et al., 2019), D'Alincourt (Silva, et al., 2019) e Tinguí (Santos, et al., 2019), no estado de Rondônia. Os valores da densidade de drenagem também tendem a se elevar com o aumento da declividade (Figuras 4 e 6). Logo, a elevada densidade de drenagem na cabeceira da sub-bacia sugere que esta região é considerada prioritária para a conservação dos recursos hídricos.

O valor do índice de sinuosidade demonstra que o canal principal da sub-bacia em estudo é sinuoso. Nestas condições, ocorre a erosão do solo das margens externas do canal e o acúmulo de sedimentos nas margens internas, como ocorre no canal do rio Araguaia (Bayer \& Carvalho, 2008). Esse comportamento explica o frequente deslocamento do canal principal, e a formação de vários canais interconectados, formando um sistema fluvial anastomosado (Figura 8).

O sistema fluvial anastomosado se desenvolve em regiões úmidas e alagadas, e por apresentar canais interconectados, formam várias ilhas alongadas e recobertas por vegetação (Riccomini, Giannini \& Mancini (2000). Estes autores também descrevem que a combinação de baixa declividade dos canais e alta sinuosidade provocam extravasamentos frequentes, que resultam em deposição de silte e argila, e que a estabilidade destes canais está diretamente relacionada com a presença de vegetação. Logo é essencial, a manutenção da vegetação nativa na zona ripária. 
Figura 8. Sistema fluvial anastomosado na sub-bacia do rio Escondido,

Amazônia sul-ocidental, Brasil.

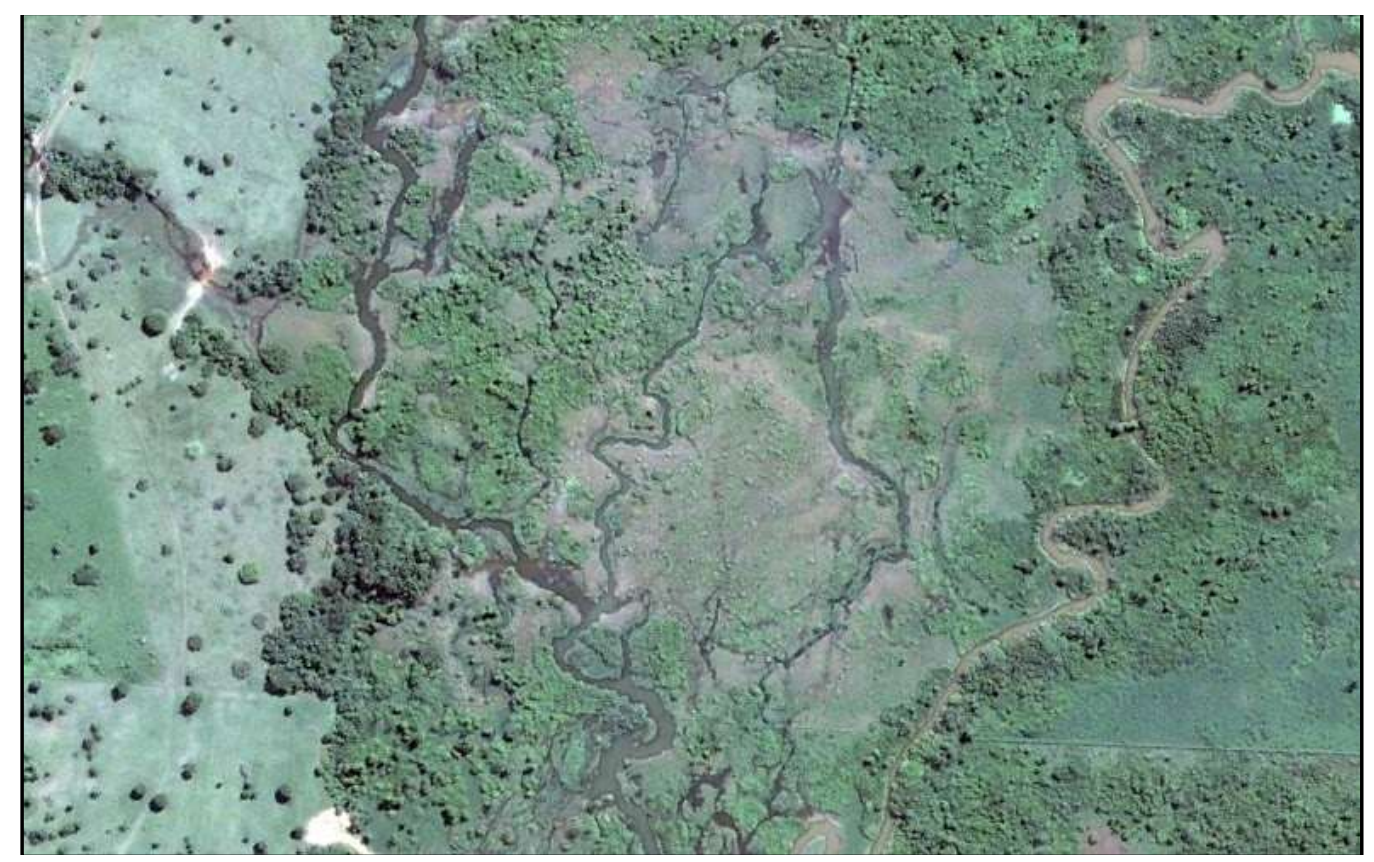

Fonte: Google Earth, (2021).

Destaca-se que a deposição de sedimentos é responsável por formar praias naturais de água doce no rio Guaporé (onde desemboca o rio Escondido). Essas áreas são importantes berçários para algumas espécies, a exemplo da Podocnemis unifilis (tracajá) (Fachín-Terán \& Vogt, 2004). Portanto, o manejo adotado na sub-bacia do rio Escondido pode vir a afetar a reprodução de espécies nativas na região do Guaporé, uma vez que os sedimentos podem conter elementos tóxicos, provenientes de sistemas agropecuários localizados nas cotas mais elevadas. Neste contexto, constata-se a importância do manejo adequado na agropecuária e manutenção das matas ciliares nas zonas ripárias.

O coeficiente de manutenção é considerado baixo quando comparado com os coeficientes das microbacias dos rios Mutum, D'Alincourt, Tinguí, Manicoré e Gavião, os quais têm valores de 499, 495, 465, 433 e $1.250 \mathrm{~m}^{2} \mathrm{~m}^{-1}$, respectivamente (Souza, et al., 2021; Santos, et al., 2019; Silva, et al., 2019; Vendruscolo, et al., 2019; Donegá, et al., 2021). Portanto, é necessária uma área menor para a manutenção dos cursos d'água na sub-bacia do rio Escondido, em comparação com as microbacias citadas.

É importante ressaltar que os valores do coeficiente de manutenção também variam dentro da sub-bacia. Na microbacia do rio Enganado, localizado na cabeceira da sub-bacia, o coeficiente é de $347 \mathrm{~m}^{2} \mathrm{~m}^{-1}$ (Moreto, et al., 2019), contudo, na microbacia do rio Santa Teresinha, localizada próxima ao exutório da sub-bacia, o coeficiente é de $2.439 \mathrm{~m}^{2} \mathrm{~m}^{-1}$ (Soares, et al., 2019). Em face ao exposto, constata-se a importância de se trabalhar com microbacias para obtenção de informações destinadas ao manejo regional.

O tempo de concentração de 28,38 h é considerado alto, visto que uma precipitação pluviométrica dificilmente terá essa duração, reduzindo a possibilidade de toda área contribuir simultaneamente para a formação de enchentes. Em trabalho realizado por Santos Neto (2014) no município de Porto Velho/RO, com dados de 5.380 precipitações pluviométricas, constatou-se que $86 \%$ dos eventos duraram $\leq 3 \mathrm{~h}, 10 \%$ duraram entre 4 e $6 \mathrm{~h}$, e apenas $4 \%$ duraram $\geq 7 \mathrm{~h}$ ( 3 com duração de $16 \mathrm{~h}$ ).

O rio Escondido desemboca no rio Guaporé, e apesar da sub-bacia ter alto tempo de concentração e não ser geometricamente propensa a enchentes, ocorre a inundação sazonal na região de encontro dos rios. Esta região está inserida no pantanal 
do rio Guaporé, formado pelo extravasamento da calha principal e inundações das áreas de várzeas no período das chuvas (Santos \& Mota, 2017).

\section{Conclusão}

A sub-bacia do rio Escondido tem área de $1.595,66 \mathrm{~km}^{2}$, perímetro de $267,25 \mathrm{~km}$, forma alongada, baixa suscetibilidade a enchentes, altitudes de 182 a 597 m, predominância dos relevos suave ondulado (45,84\%), ondulado (28,28\%) e plano (19,57\%), baixa influencia a propagação de incêndios e aptidão à mecanização agrícola em 87,03\% da área, rede de drenagem de 4.183,09 km, padrão de drenagem dendrítico de $8^{\mathrm{a}}$ ordem, média densidade de nascentes, alta densidade de drenagem, canal principal sinuoso com 133,44 km de extensão, baixo coeficiente de manutenção e alto tempo de concentração.

As informações obtidas por meio de sensoriamento remoto permitiram uma análise da paisagem na sub-bacia do rio Escondido. Estas informações podem ser utilizadas para o planejamento de estratégias visando o desenvolvimento sustentável da região.

É recomendado uma análise da dinâmica da cobertura do solo, considerando as características topográficas e hidrográficas da sub-bacia do rio Escondido, para delimitar as áreas prioritárias para conservação e recuperação da vegetação nativa. Devido a grande dimensão da sub-bacia, recomenda-se um planejamento integrado de manejo dos recursos naturais, com base em subunidades de gestão, formadas pelas microbacias, por apresentarem características de paisagem diferenciadas que influenciam as práticas de manejo.

\section{Referências}

Alvares, C. A, Stape, J. L., Sentelhas, P. C., Gonçalves, L. M., \& Sparovek, G. (2014). Köppen's climate classification map for Brazil. Meteorologische Zeitschrift, 22(6), 711-728. 10.1127/0941-2948/2013/0507

Amorim, R. S. S., Silva, D. D., Pruski, F. F., \& Matos, A. T. (2001). Influência da declividade do solo e da energia cinética de chuvas simuladas no processo de erosão entre sulcos. Revista Brasileira de Engenharia Agrícola e Ambiental, 5(1), 124-130, 2001. 10.1590/S1415-43662001000100023

ASF - Alaska Satellite Facility (2017). Imagem altimétrica. https://www.asf.alaska.edu/

Bayer, M., \& Carvalho, T. M. (2008). Processos morfológicos e sedimentos no canal do rio Araguaia. Revista de Estudos Ambientais, 10(2), 24-31.

Beltrame, A.V. (1994). Diagnóstico do meio ambiente físico de bacias hidrográficas: modelo de aplicação: Universidade Federal de Santa Catarina.

Bertoni, J., \& Lombardi Neto, F. (2014). Conservação do solo. Editora Ícone.

Bourke, R. M. (2010). Altitudinal limits of 230 economic crop species in Papua New Guinea. In: Haberle, S. G., Stevenson, J., \& Prebble, M. (eds). Altered Ecologies: Fire, Climate and Human Influence on Terrestrial Landscapes: The Australian National University.

Cavallari, R. S., Tamae, R. Y., \& Rosa, A. J. (2007). A importância de um sistema de informações geográficas no estudo de microbacias hidrográficas. Revista Científica Eletrônica de Agronomia, 6 (11), 1-5.

Christofoletti, A. (1969). Análise morfométrica de bacias hidrográficas. Notícia Geomorfológica, 18(9), 35-64.

Christofoletti, A. (1980). Geomorfologia. (2a ed.), Edgard Blucher.

Cogo, N. P., Levien, R., \& Schwarz, R. A. (2003). Perdas de solo e água por erosão hídrica influenciadas por métodos de preparo, classes de declive e níveis de fertilidade do solo. Revista Brasileira de Ciência do Solo, 27(4), 743-753. 10.1590/S0100-06832003000400019

Donegá, M. V. B., Souza, T. W. S., Lima, M. M., Panza, M. R., Pacheco, F. M. P., Saraiva, J. G., Cavalheiro, W. C. S., \& Vendruscolo, J. (2021). Hydrogeomorphometric characterization in the Gavião river microbasin, Western Amazon, Brazil. Research, Society and Development, 10(1), 1-14. 10.33448/rsdv10i1.11844.

Doria, C. R. C., Araújo, T. R., Souza, S. T. C., \& Torrente-Vilara, G. (2008). Contribuição da etnoictiologia à análise da legislação pesqueira referente ao defeso de espécies de peixes de interesse comercial no oeste da Amazônia Brasileira, rio Guaporé, Rondônia, Brasil. Revista Biotemas, 21 (2), 119-132.

Duckstein, L., Fogel, M. M., \& Thames, J. L. Elevation effects on rainfall: a stochastic model. Journal of Hydrology, 18, 21-35, 1973.

Fachín-Terán, A., \& Vogt, R. (2004). Estrutura populacional, tamanho e razão sexual de Podocnemis unifilis (Testudines, Podocnemididae) no rio Guaporé (RO), norte do Brasil. Phyllomedusa, 3(1), 29-42. 10.11606/issn.2316-9079.v3i1p29-42

Fairfull, S., \& Witheridge, G. (2003). Why do Fish Need to Cross the Road? Fish Passage Requirements for Waterway Crossings: NSW Fisheries. 
Fernandes, L. C., \& Guimarães, S. C. P. (2002). Atlas Geoambiental de Rondônia. SEDAM.

Figueiredo, S. M. M., Venticinque, E. M., Figueiredo, E. O., \& Ferreira, E. J. L. (2015). Predição da distribuição de espécies florestais usando variáveis topográficas e de índice de vegetação no leste do Acre, Brasil. Acta Amazonica, 45(2), 167-174, 2015. 10.1590/1809-4392201402834

Franca, R. R. (2015). Climatologia das chuvas em Rondônia - período 1981-2011. Revista Geografias, 11(1), 44-58. https://periodicos.ufmg.br/index.php/geografias/article/view/13392/10624

Fritzsons, E., Mantovani, L. E., \& Aguiar, A. V. (2008). Relação entre altitude e temperatura: uma contribuição ao zoneamento climático no estado do Paraná. Revista de Estudos Ambientais, 10(1): 49-64, 2008. 10.7867/1983-1501.2008v10n1p49-64

Fritzsons, E., Mantovani, L. E., \& Wrege, M. S. (2016). Relação entre altitude e temperatura: uma contribuição ao zoneamento climático no estado de Santa Catarina, Brasil. Revista Brasileira de Climatologia, 12(8), 80-92, 2016. 10.5380/abclima.v18i0.39471

Fritzsons, E., Wrege, M. S., \& Mantovani, L. E. (2015). Altitude e temperatura: estudo do gradiente térmico no Rio Grande do Sul. Revista Brasileira de Climatologia, 11(16), 108-119, 2015. 10.5380/abclima.v16i0.39665

Girão, O., \& Corrêa, A. C. B. (2004). A contribuição da geomorfologia para o planejamento da ocupação de novas áreas. Revista de Geografia, 21(2), 36-58.

Guerra, A. J. T. (1997). Ravinas: processo de formação e desenvolvimento. Anuário do Instituto de Geociências, $20,9-26$.

Horton, R. E. (1932). Drainage basin characteristics. Transactions, American Geophysical Union, 13(1), 350-361.

INCRA - Instituto Nacional de Colonização e Reforma Agrária (2018). Acervo fundiário. http://acervofundiario.incra.gov.br/acervo/acv.php.

Kabite, G., \& Gessesse, B. (2018). Hydro-geomorphological characterization of Dhidhessa River Basin, Ethiopia. International Soil and Water Conservation Research, 6, 175-183. 10.1016/j.iswcr.2018.02.003

Lima Júnior, J. C., Vieira, W. L., Macêdo, K. G., Souza, S. A., \& Nascimento, F. A. L. (2012). Determinação das características morfométricas da sub-bacia do Riacho Madeira Cortada, Quixelô, CE. VII Congresso Norte-Nordeste de Pesquisa e Inovação. Palmas-TO: Instituto Federal de Educação, Ciência e Tecnologia. p. $1-7$.

Lollo, J. A. (1995). O uso da técnica de avaliação do terreno no processo de elaboração do mapeamento geotécnico: sistematização e aplicação na quadrícula de Campinas: Universidade de São Paulo.

Miranda, I. S., Almeida, S. S., \& Dantas, P. J. (2006). Florística e estrutura de comunidades arbóreas em cerrados de Rondônia, Brasil. Acta Amazônica, 36(4), 419-430, 2006. 10.1590/S0044-59672006000400004

Moreto, R. F., Mira, S. F., Soares, G. S., Santos Junior, N. R. F., Cavalheiro, W. C. S, Vendruscolo, J., \& Rosa, D. M. (2019). Características geométricas, topográficas e hidrográficas da microbacia do rio Enganado, região sul da Amazônia Ocidental. Revista Geográfica Venezolana, especial, 110-124. http://www.saber.ula.ve/handle/123456789/46159

Nery Junior, H., \& Vanzela, L. S. (2016). Influência do relevo sobre a distribuição espacial da precipitação no município de Caraguatatuba - SP. In. XII Simpósio Brasileira de Climatologia Geográfica: ABClima.

Parvis, M. (1950). Drainage pattern significance in airphoto identification of soils and bedrocks. Photogrammetric Engineering, 16, $387-408$.

Pereira, A. S., Shitsuka, D. M., Parreira, F. J., \& Shitsuka, R. (2018). Metodologia da Pesquisa Científica. Universidade Federal de Santa Maria. https://repositorio.ufsm.br/bitstream/handle/1/15824/Lic_Computacao_Metodologia-Pesquisa-Cientifica.pdf?sequence=1

QGIS Development Team. (2015). QGIS Geographic Information System. Open Source Geospatial Foundation Project. http://qgis.osgeo.org

Ribeiro, L., Koproski, L. P., Stolle, L., Lingnau, C., Soares, R. V., \& Batista, A. C. (2008). Zoneamento de riscos de incêndios florestais para a Fazenda Experimental do Canguiri, Pinhais (PR). Floresta, 38(3), 561-572. 10.5380/rf.v38i3.12430

Riccomini, C., Giannini, P. C. F., \& Mancini, F. (2000). Rios e processos aluviais. In: Teixeira, W., Fairchild, T. R., Toledo, M. C. M., \& Taioli, F. Decifrando a Terra. Companhia Editora Nacional.

Romero, V., Formiga, K. T. M., \& Marcuzzo, F. F. N. (2017). Estudo hidromorfológico de bacia hidrográfica urbana em Goiânia/GO. Ciência e Natura, 39(2), 320-340. 10.5902/2179460X26411

Santos, A. M., \& Mota, V. C. (2017). Análise espacial dos usos e da cobertura da terra no pantanal dos rios Guaporé e Mamoré/Rondônia. Revista Brasileira de Geomática, 5(3), 433-452.

Santos, A. M., Targa, M. S., Batista, G. T., \& Dias, N. W. (2012). Análise morfométrica das sub-bacias hidrográficas Perdizes e Fojo no município de Campos do Jordão, SP, Brasil. Revista Ambiente \& Água, 7(3), 195-211. 10.4136/1980-993X

Santos Neto, L. A. (2014). Variabilidade da precipitação horária em Porto Velho - RO e suas tendências anuais e sazonais: Universidade Federal de Rondônia.

Santos, L. P., Rosa, D. M., Cavalheiro, W. C. S., Vendruscolo, J., Rosell, E. C. F., Biggs, T., \& Stachiw, R. (2019). Hidrogeomorfometria e índice de desmatamento da microbacia do rio Tinguí, Amazônia Ocidental, Brasil. Revista Geográfica Venezolana, especial: 40-56. http://www.saber.ula.ve/handle/123456789/46154.

Santos, R. D., Lemos, R. C., Santos, H. G., Ker, J. C., Anjos, L. H. C., \& Shimizu, S. H. (2013). Manual de descrição e coleta de solo no campo. Viçosa-MG: Sociedade Brasileira de Ciência do Solo. 
Research, Society and Development, v. 10, n. 3, e22210313253, 2021

(CC BY 4.0) | ISSN 2525-3409 | DOI: http://dx.doi.org/10.33448/rsd-v10i3.13253

SEDAM - Secretaria de Estado do Desenvolvimento Ambiental (2012). Boletim Climático de Rondônia - 2010. SEDAM.

Silva, A. F., Tronco, K. M., Vendruscolo, J., Oliveira, J. N., Cavalheiro, W. C. S., Rosa, D. M., \& Stachiw, R. (2019). Geoprocessamento aplicado a hidrogeomorfometria e índice de desflorestamento na microbacia do rio D'Alincourt, Amazônia Ocidental, Brasil. Revista Geográfica Venezolana, especial, $210-235$.

Silva, E. C., Praia, W. M., Santos, A. S., Cardoso, L. A. P., Hara, F. A. S., Cavalheiro, W. C. S., \& Vendruscolo, J. (2021). Características hidrogeomorfométricas da microbacia Três Galhos, Amazônia Ocidental, Brasil. Research, Society and Development, 10(2), 1-17, 2021. 10.33448/rsd-v10i2.12408

Silva, F. M., Rezende, F. A., Alves, H. M. R., Alves, M. C., Moreira, M. A., \& Silva, A. C. (2009). Potencialidade de mecanização da região Sul e Sudoeste de Minas Gerais, visando a lavoura cafeeira. In.: VI Simpósio de Pesquisa dos Cafés do Brasil: EMBRAPA, 1-6.

Silva, R. G. C., \& Dandolini, G. (2018). Conflitos agrários e acesso à terra em Rondônia. Revista Direito e Práxis, 9(1), 461-479. 10.1590/2179$8966 / 2018 / 32712$.

Silva, Q. D. (2012). Mapeamento geomorfológico da Ilha do Maranhão: Universidade Estadual Paulista.

Soares, G. S., Santos Júnior, N. R. F., Mira, S. F., Moreto, R. F., Cavalheiro, W. C. S., Vendruscolo, J., \& Rosa, D. M. (2019). Uso de plataforma SIG na caracterização morfométrica da microbacia do rio Santa Teresinha, Amazônia Ocidental, Brasil. Revista Geográfica Venezolana, especial, 84-95. http://www.saber.ula.ve/handle/123456789/46157

Souza, T. W. S., Lima, M. M., Saraiva, J. G., Pacheco, F. M. P., Donegá, M. V. B., Panza, M. R., Cavalheiro, W. C. S., \& Vend ruscolo, J. (2021). Análise hidrogeomorfométrica da microbacia do rio Mutum: informações para auxiliar o manejo de recursos hídricos na Amazônia Ocidental. Research, Society and Development, 10(2), 1-17. 10.33448/rsd-v10i2.12448

Targa, M. S., Batista, G. T., Diniz, H. D., Dias, N. W., \& Matos, F. C. (2012). Urbanização e escoamento superficial na bacia hidrográfica do Igarapé Tucunduba, Belém, PA, Brasil. Revista Ambiente \& Água, 7(2), 120-142. 10.4136/1980-993X

Tucci, C. E. M. (2004). Hidrologia: ciência e aplicação. Editora UFRGS.

Vendruscolo, J., Cavalheiro, W. C. S., Rosa, D. M., Stachiw, R., Vendruscolo, R., Siqueira, A. S., \& Biggs, T. (2019). Hidrogeomorfometria e desmatamento na microbacia do rio Manicoré, Amazônia Ocidental, Brasil. Revista Geográfica Venezolana, especial, 226-241.

Vendruscolo, J., Pacheco, F. M. P., Ramos, H. F., Cavalheiro, W. C. S., \& Rodrigues. A. A. M. (2020a). Hidrogeomorfometria da microbacia Alto Rio Escondido: informações para auxiliar o manejo dos recursos naturais na Amazônia ocidental. Brazilian Journal of Development, 6(3), 9709-9730. 10.34117/bjdv6n3-011

Vendruscolo, J., Pacheco, F. M. P., Rodrigues, A. A. M., Ramos, H. F., Rosa, D. M., \& Cavalheiro, W. C. S. (2020b). Características morfométricas da microbacia do Médio Rio Escondido, Amazônia Ocidental, Brasil. Brazilian Journal of Development, 6(1), 565-585. 10.34117/bjdv6n1-040

Villela, S. M., \& Mattos, A. (1975). Hidrologia aplicada. McGraw-Hill. 